\title{
LIDERANÇA: ATIVO ESTRATÉGICO DO PODER JUDICIÁRIO
}

\author{
LEADERSHIP: STRATEGIC ASSETS OF JUDICIAL POWER
}

FRANCISCO EDUARDO FONTENELE BATISTA

Mestrando em direito pela Enfam. Especialista em processo civil pela UFC. Professor dos cursos de pós-graduação e de formação inicial e continuada de magistrados da Esmec. Juiz de direito do TJCE. https://orcid.org/0000-0003-4084-3021

LUIZA VIEIRA SÁ DE FIGUEIREDO

Docente permanente e orientadora do PPGPD/Enfam. Formadora da Enfam, atua em programas de formação inicial, continuada e EaD. Coordenadora pedagógica da Ejud-MS. Pesquisadora voluntária do Grupo Cadef/UFMS Movimento Espacial de Fronteira; colaboradora voluntária do Mestrado em

Estudos Fronteiriços - UFMS - Campus Pantanal. https://orcid.org/0000-0002-6407-3570

\section{RESUMO}

Após a criação do Conselho Nacional de Justiça como órgão da cúpula administrativa do Poder Judiciário, muito se evoluiu em termos de planejamento e estratégia. Entretanto, ainda é preciso avançar nas políticas de gestão de pessoas. Neste trabalho, propõe-se que a liderança seja compreendida como ativo estratégico da organização. 0 estudo da liderança foi inicialmente orientado à pessoa e com o tempo passou a ser direcionado à situação, falando-se em liderança situacional. Atualmente, está voltado à interação, ganhando dinamicidade nas relações construídas no ambiente de trabalho, com enfoque no desenvolvimento humano e reflexo na efetividade das atividades organizacionais. Nesse contexto, faz-se necessário o alinhamento da gestão de pessoas à estratégia judiciária, com o desenvolvimento de competências específicas pelos magistrados e servidores do Poder Judiciário, por conta das mudanças experimentadas na sociedade contemporânea. Defende-se que a compreensão da liderança como ativo estratégico do Poder Judiciário refletirá nas estratégias a serem implementadas pelos tribunais e, consequentemente, em maior eficiência no cumprimento de sua missão. 
Palavras-chave: Poder Judiciário; estratégia; gestão de pessoas; competências; eficiência.

\section{ABSTRACT}

After the creation of the National Council of Justice as an organ of the administrative summit of the Judiciary, much has changed in terms of planning and strategy. However, there is still a need to advance in people management policies. In the present work, it is proposed that Leadership is understood as a strategic asset of the organization. The study of leadership was initially oriented to the person and over time started to be directed to the situation, talking about situational leadership. Currently, it is focused on interaction, gaining dynamism in the relationships built in the work environment, with a focus on human development and reflected in the effectiveness of organizational activities. In this context, it is necessary to align people management to the judicial strategy, with the development of specific skills by judges and civil servants of the Judiciary, due to the changes experienced in contemporary society. It is argued that the understanding of Leadership as a strategic asset of the Judiciary Power will reflect in the strategies to be implemented by the Courts and, consequently, in greater efficiency in the fulfillment of its mission.

Keywords: Judicial Power; strategy; people management; skills; efficiency.

Recebido: 24-5-2021

Aprovado: 28-6-2021

\section{SUMÁRIO}

1 Introdução. 2 Crise, gestão judiciária e os caminhos para a superação. 3 Gestão de pessoas adequada e alinhamento estratégico. 4 Liderança e desenvolvimento de competências na execução da estratégia judiciária. 5 Conjugação de competências no Poder Judiciário e eficiência. 6 Conclusão. Referências. 


\section{INTRODUÇÃO}

Após a criação do Conselho Nacional de Justiça - CNJ pela Emenda Constitucional n. 45/2004, conhecida como a Reforma do Poder Judiciário, muito se avançou no Poder Judiciário em termos de planejamento estratégico. A atuação do CNJ teve papel preponderante na organização de diretrizes nacionais, no aperfeiçoamento de técnicas administrativas e na aproximação dos tribunais, que passaram a trocar experiências em torno de medidas de gestão.

A reforma empreendida é resultante da grande insatisfação da sociedade com o funcionamento da instituição. Desde o advento da referida emenda, o Judiciário viu-se obrigado a realizar grandes investimentos na modernização de sua estrutura e gestão administrativa, aproveitando, inclusive, métodos e técnicas próprias a outras ciências, estando, hoje, em um contexto de crescente judicialização, a perseguir resultados amparado em estratégia gerencial voltada principalmente para a realização de baixas processuais, na tentativa de superar a grave crise de legitimidade que o aflige.

Mantendo-se elevada a litigiosidade, porém, o esforço empreendido pela governança judiciária ainda não atingiu todas as suas potencialidades, colaborando para isso a falta de um tratamento adequado de conflitos por parte da legislação, que não oferece os estímulos capazes de tornar mais racional o uso da máquina judiciária pelo jurisdicionado, como a fixação de custas economicamente mais ajustadas, a imposição de critérios objetivos para a concessão da gratuidade judiciária, o tratamento adequado das demandas repetitivas e o uso dos métodos autocompositivos na via pré-processual obrigatória, dentre outros. Premido pelo cumprimento de metas, o Judiciário tem se esforçado para alcançar a eficiência por meio da prestação jurisdicional célere e eficaz.

Internamente, reconhece-se como insumo para a construção dessa conjuntura, na qual ainda não se atingiu o máximo de eficiência, a falta de alinhamento pelo Judiciário de todos os recursos de que pode lançar mão na sua estratégia. O termo "estratégia" norteia todo o processo de evolução da humanidade, aplicando-se em cada tipo e organização desenvolvida pelo homem, de modo a obterem-se vantagens em disputas por posicionamento, seja na guerra, seja entre nações, empresas ou mercados. (ALEXANDRE et al. apud FIGUEIREDO, 2014, p. 29) 
Ao longo do tempo, deixou-se de lado a visão de estratégia como plano, passando a concebê-la como um processo de atividade contínua. O conceito de estratégia está diretamente relacionado com medidas concebidas em uma situação atual, visando interceptar o futuro, ou seja, "construir oportunidades futuras por meio de um desenho bem definido". (HAMEL; PRAHALAD apud ALEXANDRE et al., 2006)

Na visão organizacional, estratégia é:

[...] uma somatória de planos e ações integradas que, considerando as frequentes variações ambientais, visa assegurar vantagens competitivas contínuas, geradoras de estímulos internos à sua estrutura social e de diferenciações excelentes de seus produtos e/ou serviços. (ARAÚJO; GARCIA, 2010, p. 357)

No setor público, estratégia é "definir os objetivos da organização e buscar a sintonia com as demandas da população" a longo prazo, levando em consideração as aspirações da sociedade em relação à organização pública. (MATIAS-PEREIRA, 2012, p. 116)

Atualmente, o acionamento e o engajamento de todos os recursos disponíveis no cumprimento da missão institucional são medidas necessárias em todas as instituições, públicas ou privadas, diante das mudanças por que tem passado o mundo nos últimos anos, não podendo, por essa razão, deixar de alcançar aquele que é o maior ativo ou patrimônio de uma organização: as pessoas.

Neste artigo, pretende-se relacionar as premissas da Política de Gestão de Pessoas no âmbito do Poder Judiciário com as modernas teorias da liderança, percebendo a liderança como ativo estratégico da organização, em uma perspectiva transversal, perpassando o capital social organizacional, o capital humano e o capital organizacional.

O estudo da liderança foi inicialmente orientado à pessoa e com o tempo passou a ser direcionado à situação, falando-se em liderança situacional. Atualmente, está orientado à interação, ganhando dinamicidade nas relações construídas no ambiente de trabalho, com enfoque no desenvolvimento humano e reflexo na efetividade das atividades organizacionais.

Nesse contexto, faz-se necessário o alinhamento da gestão de pessoas à estratégia judiciária, com o desenvolvimento de competências específicas no quadro de colaboradores do Judiciário, por conta 
das mudanças experimentadas na sociedade contemporânea. É imprescindível que sejam fomentados o desenvolvimento e a prática de conhecimentos técnicos juntamente com aqueles que vêm assumindo cada vez maior importância no contexto corporativo, qual seja, das competências socioemocionais, com as quais os primeiros devem ser conjugados nos processos de trabalho da instituição.

A necessidade de repensar o papel do trabalho desenvolvido a partir da conjugação dessas competências decorre da maior exigência do cumprimento de metas, do crescente dinamismo das relações sociais e da velocidade na produção de conhecimento e transmissão de informações na atualidade, a demandar constantemente a coordenada, focada e sinérgica atuação de todos os componentes da instituição, independente do cargo ocupado, na execução de sua estratégia.

Pautando-se desde a reforma do Judiciário sua governança pelos ensinamentos vindos da ciência da administração e da economia que demandam, no desencargo de suas atribuições, a busca dos valores da máxima eficiência com o mínimo de custo envolvido, torna-se imprescindível o reajuste do enfoque conferido à gestão de pessoas, voltando-o com vigor à consecução dos fins estratégicos do Poder Judiciário.

\section{CRISE, GESTÃO JUDICIÁRIA E OS CAMINHOS PARA A SUPERAÇÃO}

A implementação de uma política de bem-estar social no Estado brasileiro redemocratizado, somada à inerente constitucionalização de inúmeros direitos sociais, ensejou uma grande onda de litigância.

A sociedade brasileira - ansiosa pela concretização da cidadania plena, por décadas frustrada durante o periodo ditatorial - via-se agora prenhe de direitos e apta a judicializar suas queixas e demandas, contando com o amparo de complexo normativo-constitucional dotado de normas programáticas de direitos sociais nunca positivados, gerados no intento de reduzir a desigualdade social e promover a dignidade, e de um conjunto de regras e princípios, com igual status de fundamentalidade dos novos direitos, destinado a Ihes garantir a exequibilidade.

A rede de proteção judicial instituída pela Constituição trouxe consigo desde a positivação do próprio direito de acesso à justiça (art. 5, $\times X X V$ ), também chamado de direito à inafastabilidade de 
controle jurisdicional, à previsão de instituição de defensorias públicas (art. 21, inciso XIII; art. 134) e de juizados especiais (art. 24, inciso X), estimulando o cidadão a buscar o Estado-Juiz para concretizar as previsões normativas de proteção da dignidade, mesmo quando não dispusesse de recursos para tal fim, por meio do acesso à gratuidade da justiça (art. 5ํ, LXXIV). (BRASIL, 1998)

A grande litigância gerada por esse quadro impactou negativamente o Poder Judiciário, que não estava estrutural e funcionalmente preparado para a considerável elevação da demanda e para reformulação de seu papel político, uma vez alçado à condição de guardião da Constituição e de garantidor dos direitos sociais. O massivo e inevitável congestionamento dos órgãos judiciais resultante desse panorama só fortaleceu as críticas já existentes acerca da sua (in)eficiência.

○ Judiciário, então, na esteira das grandes mudanças administrativas vivenciadas no âmbito da administração pública federal, e do próprio restante do Estado brasileiro, acabou passando por uma grande reforma estrutural com a promulgação da Emenda Constitucional n. 45/2004. Mudando paradigmas, a norma impôs nova mentalidade gerencial ao Judiciário, conferiu-Ihe perfil de ente prestador de serviços e trouxe para o foco da gestão judiciária o cidadão, o jurisdicionado, demandando da instituição sua reestruturação em instrumento de eficiência na realização de direitos.

A necessidade de uma prestação jurisdicional eficiente levou o Judiciário a apropriar-se de técnicas, metodologias e ideologias de gestão praticadas pela iniciativa privada para a consecução de seus objetivos. O fim ambicionado não era o lucro financeiro, mas o lucro social (LIMBERGER; KOSSMANN, 2016), conceito que, ligado diretamente à ideia de efetividade, representa-se na concreta fruição dos direitos passível de alcance por quem dos seus serviços se valer. Considerado o contexto de congestionamento, grande litigiosidade e a busca da eficiência, a alta administração do Judiciário convencionou promover a redução quantitativa de acervos como meio de erradicação do problema, priorizando-se os processos mais antigos, ou seja, que tramitavam há mais tempo.

Em 18 de março de 2009, foi editada pelo Conselho Nacional de Justiça a Resolução n. 70, que dispôs sobre o Planejamento e a Gestão Estratégica no âmbito do Poder Judiciário. Na ocasião, considerouse que a unicidade do Poder Judiciário exigia a implementação de diretrizes nacionais para nortear a atuação institucional de todos os 
seus órgãos, bem como a necessidade de se conferir maior continuidade administrativa aos tribunais, independentemente da alternância bienal de seus gestores.

A edição da referida resolução foi também subsidiada pelo I e II Encontro Nacional do Judiciário, no qual foram aprovadas as 10 Metas Nacionais de Nivelamento para o ano de 2009, dentre as quais a conhecida Meta 2, que consistia em identificar os processos judiciais mais antigos e adotar medidas concretas para o julgamento de todos os processos distribuídos até 31 de dezembro de 2005.

Em 2010, por ocasião do III Encontro Nacional do Judiciário, foram definidas mais 10 Metas Prioritárias para o ano, dentre as quais, o julgamento de quantidade igual à de processos de conhecimento distribuídos em 2010 e parcela do estoque (Meta 1); o julgamento de todos os processos de conhecimento distribuídos até 31 de dezembro de 2006 (Meta 2); e a previsão de redução do acervo de processos de execução: em pelo menos 10\% o acervo de processos na fase de cumprimento ou de execução e, em 20\%, o acervo de execuções fiscais (Meta 3).

As metas continuam se reproduzindo ano a ano. São votadas e aprovadas pelos presidentes dos tribunais no Encontro Nacional do Poder Judiciário - ENPJ, organizado pelo Conselho Nacional de Justiça, que reúne a alta administração dos tribunais brasileiros. A referida Resolução n. 70 foi substituida pela Resolução n. 198, de 1ำ de julho de 2014, que consolidou macrodesafios do Poder Judiciário para o sexênio 2015-2020, formulados pela Rede de Governança Colaborativa e aprovados no VII Encontro Nacional do Judiciário, em novembro de 2013.

A Rede de Governança Colaborativa do Poder Judiciário é composta por representantes dos órgãos desse poder e objetiva propor diretrizes relacionadas com a Estratégia Nacional do Poder Judiciário, impulsionar sua implementação, monitorar e divulgar os resultados, bem como atuar em temas voltados à governança judiciária, buscando a melhoria dos serviços jurisdicionais (CONSELHO NACIONAL DE JUSTIÇA, 2019).

A ordem é promover uma ideologia gerencial direcionada para resultados e para o alto desempenho, amparada por massivo investimento em material, maquinário, informatização, estrutura, serviços e na redefinição de responsabilidades, atribuições, competências e 
processos de trabalho, dentre outras medidas. A efetiva consecução dessa finalidade reclama até hoje a construção de uma estratégia clara e duradoura de atuação envolvendo todos os setores desse poder e a sociedade.

Os trabalhos desenvolvidos no âmbito do Comitê Gestor Nacional da Rede de Governança Colaborativa do Poder Judiciário subsidiaram a Estratégia Nacional do Poder Judiciário para o período 2021-2026, ao estabelecer expressamente que os órgãos do Judiciário:

Deverão promover a participação de magistrados de primeiro e segundo graus, ministros, servidores e demais integrantes do sistema judiciário e de entidades de classe na elaboração de seus planejamentos estratégicos, garantida a contribuição da sociedade. (CONSELHO NACIONAL DE JUSTIÇA, 2020)

O referido normativo, além de consolidar a promoção da redução quantitativa de acervos, priorizando-se os processos mais antigos?', estabeleceu expressamente que "a execução da Estratégia Nacional do Poder Judiciário é de responsabilidade de ministros, conselheiros, magistrados de primeiro e segundo graus, servidores e colaboradores do Poder Judiciário".

Os relatórios de acompanhamento publicados pelo Conselho Nacional de Justiça (2021) no seu portal evidenciam a dificuldade dos tribunais no cumprimento integral das metas nacionais. O ajuste da metodologia de gestão dos processos de trabalho ao perfil administrativo e à missão a ser desempenhada pelo novo Judiciário, mais tecnológico e funcionalmente engajado no aumento da produtividade, por meio do descongestionamento de seus acervos, deve integrar a estratégia para a eficiência.

Afinal, será mais eficiente o Judiciário quanto mais for competente, por meio de sua força de trabalho, em gerenciar (e julgar) os processos sob sua responsabilidade, distribuindo justiça e realizando direitos. Cabe, portanto, à governança judicial traçar metas, planejar-se

Art. 13, Resolução n. 325: A Meta Nacional 1 - Julgar mais processos que os distribuídos e a Meta Nacional 2 - Julgar processos mais antigos, que visam, respectivamente, à prevenção de formação de estoque e à redução de passivo processual, comporão obrigatoriamente o monitoramento da Estratégia Nacional do Poder Judiciário 20212026. (CONSELHO NACIONAL DE JUSTICCA, 2020) 
estrategicamente e organizar-se para que, acionando e valendo-se de todos os recursos disponíveis, seja alcançado o desempenho excelente, prestando a jurisdição de forma eficiente e em tempo razoável.

Nesse contexto, o engajamento das pessoas, enquanto responsáveis pela execução de todos os serviços, na missão institucional do Judiciário se faz imprescindível. É por meio de seu trabalho que se julgam processos, resolvem-se conflitos e se reduzem os acervos. É natural, portanto, que se busque desse grupo de agentes públicos, composto de magistrados, servidores e colaboradores, melhor performance no cumprimento das metas de produtividade e de redução do congestionamento de acervo.

\section{GESTÃO DE PESSOAS ADEQUADA E ALINHAMENTO ESTRATÉGICO}

Ativos de uma organização são bens e direitos que representam valor e proporcionam ganhos. Nas organizações privadas, o objetivo do trabalho gerencial é claro: oferecer produtos e serviços que tragam lucro para a empresa. As organizações públicas, entretanto, norteiamse essencialmente por outras premissas. Na medida em que devem realizar sua função social, o valor e os ganhos não são representados por índices monetários ou financeiros, embora esses também façam parte da sua existência. $\bigcirc$ foco é outro.

Nesse contexto, fala-se em ativos estratégicos das organizações públicas: o capital social organizacional, caracterizado por relações sociais, confiança mútua, aprendizado compartilhado; o capital humano, constituído por conhecimentos, habilidades, experiências individuais, criatividade; e o capital organizacional, formado pela cultura organizacional, pela reputação, pelos processos de produção e direitos de propriedade intelectual. (FIGUEIREDO, 2014, p. 35)

As pessoas são responsáveis pela formação desses ativos e, por isso, a gestão de pessoas na modernidade assume um papel preponderante na estrutura e na estratégia da organização, porquanto "a atenção dispensada nas políticas voltadas ao recurso humano reflete na qualidade dos serviços prestados e por consequência na satisfação do cidadão" (ALMEIDA; SANTOS apud FIGUEIREDO, 2014, p. 149). Afinal, é o material humano que caracteriza uma organização (BARNARD apud 
LODI, 1971). As organizações públicas, sobretudo, são sistemas sociais cuja existência deve encontrar fundamento na cooperação humana entre seus agentes, face a um propósito comum. Na lição de Bergue:

[...] a gestão de pessoas envolve um conjunto de ações preliminares de planejamento das necessidades mútuas entre as organizações e as pessoas, seguindo os esforços de direção desse conjunto, orientados pelo valor resultante do produto dos objetivos institucionais e individuais, constantemente balizado pelo cotejo entre o desempenho efetivo e previsto com vistas às correções no curso do processo. (BERGUE, 2007 apud SANTOS, 2014, p. 211)

Apesar de todo o investimento realizado na reestruturação e profissionalização de sua gestão por meio do estabelecimento de metas, da busca de resultados, da modernização tecnológica e da implantação da accountability, o Judiciário não tem caminhado com a mesma assertividade no aproveitamento ótimo daquele que é numericamente o maior recurso disponível para o cumprimento de suas funções: as pessoas. Tal como ocorre na inciativa privada em relação a seus colaboradores, os recursos humanos são o instrumental mais importante do Judiciário, seu asset management mais numeroso, e, como tal, reclama especial atenção em seu gerenciamento.

Há que se formular política capaz de proporcionar o pleno aproveitamento do trabalho dos agentes públicos, considerando as balizas e fins traçados no plano de enfrentamento das dificuldades por que passa o Judiciário, sem descuidar da valorização e do desenvolvimento do agente nesse processo, de modo que se implemente uma relação institucional sinérgica, com mútuo aproveitamento, constituindo-se verdadeira simbiose.

Uma adequada gestão de pessoas não pode ser relegada a segundo plano no projeto de reestruturação das ações do Judiciário na busca da almejada eficiência. É responsabilidade da governança judiciária providenciar não só a promoção do perfeito alinhamento do gerenciamento dos recursos humanos a partir da visão, missão e da própria estratégia da instituição, como o incentivo a que, nesse processo, seja o agente público tratado como "elemento diferenciado para o sucesso organizacional" (SANTOS, 2014, p. 211), motivando-o à prática de comportamentos desejados à luz da missão estratégica. 
O termo estratégia é aqui utilizado para caracterizar o conjunto de ações correspondentes à formulação da missão e dos objetivos de uma instituição ou organização, assim como das políticas e dos planos de ação desenhados para alcançá-Ios (ALBUQUERQUE; LEITE, 2009, p. 10). Reside nessa concepção a razão para que o padrão comportamental a ser exigido do quadro de pessoal da instituição seja por ela definida. Assim, tanto a prática de uma adequada gestão de pessoas, conjugada aos objetivos institucionais e individuais dos agentes, como seu efetivo alinhamento à estratégia da organização, apresentam-se como medidas de crucial relevância para a entrega eficiente dos serviços necessários à superação da crise do Judiciário.

Em uma perspectiva sinérgica de atuação, reclama-se, para o alcance da eficiência, que os recursos humanos sejam estimulados a adquirir e exercitar todas as competências (conhecimentos, habilidades e atitudes) necessárias à obtenção de resultados desejados pela instituição. A relação de retroalimentação entre os valores gerados pelos recursos internos nesses termos geridos e a formulação de estratégias da instituição deve, portanto, ser uma realidade, criando engajamento e benefícios no cumprimento da missão.

\section{LIDERANÇA E DESENVOLVIMENTO DE COMPETÊNCIAS NA EXECUÇÃO DA ESTRATÉGIA JUDICIÁRIA}

É no exercício do cargo judiciário que o agente público encontra o espaço para executar os conhecimentos técnicos apurados no concurso público e o ambiente no qual pode aprimorar-se e atuar como parceiro da instituição.

A Resolução n. 240, de 9 de setembro de 2016, do Conselho Nacional de Justiça, dispôs sobre a Política Nacional de Gestão de Pessoas no âmbito do Poder Judiciário. Estabeleceu como finalidade a contribuição "para o alcance dos propósitos estratégicos do Poder Judiciário e para a realização da justiça”, bem como o fomento do "aprimoramento da capacidade de atuação dos órgãos a partir do desenvolvimento profissional dos servidores e suas competências e do favorecimento à cooperação". (CONSELHO NACIONAL DE JUSTIÇA, 2016) 
Observa-se que o aprimoramento da capacidade de atuação dos órgãos deve ocorrer a partir do desenvolvimento profissional dos servidores e de suas competências. O desenvolvimento e o estímulo de competências específicas são apontados pela doutrina especializada como fator relevante nessa seara ante sua capacidade de gerar conhecimento e de estimular a aprendizagem e o engajamento voluntário necessários à execução do plano de trabalho idealizado e consolidado para o cumprimento da missão estratégica.

A competência, do ponto de vista do estudo organizacional estratégico, é a "combinação de conhecimento tácito e o conjunto de habilidades para a realização de ações produtivas", praticada sob um viés tridimensional (conhecimento, habilidade e atitude) que orienta a obtenção de um determinado fim, devendo, por essa razão, ser amparado e estimulado o seu desenvolvimento pela instituição de modo a permitir avaliar-se de que forma estão contribuindo para o desempenho da instituição. Essa transformação das competências individuais em conhecimento compartilhado e em resultados para a organização ocorre pela influência positiva de uma liderança bem exercida. (FIGUEIREDO, 2014, p. 148-149)

Liderança, segundo Hunter (2004, p. 15), "é a habilidade de influenciar pessoas para trabalharem entusiasticamente visando atingir os objetivos identificados como sendo para o bem comum". Para Santos (2010, p. 58), é "a influência interpessoal exercida em uma situação e dirigida por meio do processo de comunicação humana a diversos objetivos". Sabbag (2018, p. 145) afirma que liderança é "a habilidade de um indivíduo influenciar, motivar e habilitar outros a contribuir para a efetividade e sucesso da organização".

De sua vez, Lacombe (apud ARAÚJO; GARCIA, 2010, p. 317) aduz que liderança é "a condução de um grupo de pessoas, influenciando seus comportamentos e suas ações para atingir objetivos e metas de interesse comum desse grupo" (de acordo com uma visão do futuro baseada em um conjunto coerente de ideias e princípios). Dos conceitos relacionados, pode-se observar que o indivíduo não ocupa mais posição central, percebendo-se uma perspectiva conceitual relacional.

O estudo da liderança foi inicialmente orientado à pessoa e com o tempo passou a ser orientado à situação, falando-se em liderança situacional. Atualmente, está orientado à interação, ganhando dinamicidade nas relações construídas no ambiente de trabalho, com 
enfoque no desenvolvimento humano e reflexo na efetividade das atividades organizacionais. Sabbag (2018, p. 145-146) discorre acerca das três ondas cumulativas envolvendo a liderança.

A primeira onda, orientada à pessoa, pregava que "os líderes nascem prontos, não são fabricados". Percebia-se o líder como "inteiramente responsável pelos liderados e pelo desempenho coletivo". Os estudos eram centrados nos atributos do líder, figura naturalmente masculina, baseada no culto ao herói. Relacionavam-se os atributos do líder de acordo com o estudo de homens de sucesso e alto desempenho em grandes organizações. Assim, o líder deveria ter carisma, visão, confiança, resolutividade e otimismo.

A segunda onda, orientada à situação, surge a partir dos anos 1980, nos Estados Unidos da América. Considerou-se que "cada situação exigia certas qualidades do líder, cuja prática o moldava" e que "a liderança envolvia habilidades técnicas, administrativas e humanas". A terceira onda, da liderança orientada à interação, "considera que ocorre uma influência recíproca entre líder e liderados", em que o papel da comunicação é enfatizado e o líder deve desenvolver propósito e motivação nos liderados. Nesse contexto, só faz sentido falar em liderança quando o sujeito está inserido em um grupo. Assim, liderança é um processo social: ações e interações entre líder e liderados para atingir objetivos coletivos. (SABBAG, 2018, p. 146)

Então, a transformação de conhecimento (individual e coletivo) em resultado para a organização ocorrerá a partir da interação dos indivíduos, que devem estar alinhados em prol da consecução dos objetivos organizacionais. Sabbag (2018, p. 147) adverte que não existe liderança universal, pois toda liderança é coerente com o contexto (sociedade, ambiente), com a governança (estrutura organizacional, sistemas de decisão e comunicação) e com a cultura na qual se insere (códigos de conduta, normas, valores, relações de gênero etc.).

Observa-se que essa concepção de liderança atua transversalmente nos ativos estratégicos das organizações públicas, mencionados alhures: o capital social organizacional (relações sociais, confiança mútua, aprendizado compartilhado); o capital humano (conhecimentos, habilidades, experiências individuais, criatividade); e o capital organizacional (formado pela cultura organizacional, pela reputação, pelos processos de produção e direitos de propriedade intelectual). No 
presente artigo, ganha relevo especial o capital humano, cujo conceito se aproxima da noção de competência, a qual, por sua vez, pode ser vista sob o ponto de vista organizacional ou individual.

Para Albuquerque e Leite (2009, p. 31), a competência organizacional é um conjunto de capacidades desenvolvidas em consonância com a cultura organizacional e que devem ser geridas visando ao alcance dos objetivos organizacionais; constitui-se no resultado de sinergias positivas que ocorrem quando ativos e recursos da organização são catalisados pelas competências das pessoas. Assim, o conceito de competência "é pensado como conjunto de conhecimentos, habilidades e atitudes (isto é, conjunto de capacidades humanas) que justificam um alto desempenho".

No senso comum, a palavra é utilizada para "designar uma pessoa qualificada para realizar alguma coisa, cujo antônimo implica não apenas a negação desta capacidade, mas guarda um sentimento pejorativo, depreciativo", sinalizando que "a pessoa se encontra ou se encontrará brevemente marginalizada dos circuitos de trabalho e de reconhecimento social". (FLEURY; FLEURY, 2001, p. 184)

Trazendo a reflexão para o Poder Judiciário, como diretriz normativa da formação de magistrados, competência:

[...] é a capacidade de agir, em situações previstas e não previstas, com rapidez e eficiência, articulando conhecimentos tácitos e científicos, experiências sociais e de trabalho, comportamentos e valores, desejos e motivações desenvolvidos ao longo das trajetórias de vida em contextos cada vez mais complexos. (ENFAM, 2017, p. 10)

Essa noção está ligada:

[...] à capacidade de solucionar problemas, mobilizando, de forma inter e transdisciplinar, conhecimentos, capacidades - específicas, cognitivas complexas e comportamentais - e habilidades, transferidos para novas situações, ou seja, implica atuar mobilizando conhecimentos e recursos. (ENFAM, 2017, p. 10)

No próximo tópico, aborda-se-á de forma mais pormenorizada a noção de competência no âmbito das atividades desenvolvidas no Poder Judiciário. 


\section{CONJUGAÇÃO DE COMPETÊNCIAS NO PODER JUDICIÁ- RIO E EFICIÊNCIA}

Sabbag (2018, p. 45) defende que para focar o desenvolvimento de competências é possível classificá-las em dois grandes grupos: duras (hard) e brandas (soft). Esclarece que "em uma análise superficial, as competências de cunho técnico são duras, enquanto as relacionais são brandas". Exemplifica que "o pensamento racional objetivo determina competências duras, a sensibilidade e intuição - e a subjetividade predominam nas competências brandas".

Em suma, fala-se de competências representadas pelo conhecimento técnico propriamente dito, e outras consubstanciadas em um agrupamento de habilidades socioemocionais, possuindo ambas destacado papel para o sucesso do trabalho de qualquer organização, inclusive na judiciária.

O investimento no desenvolvimento e uso conjunto dessas competências perante o serviço judiciário tem a potencialidade de conferir maior efetividade ao trabalho desenvolvido pela instituição, devendo sua realização ser preocupação constante da governança judiciária. Nas próximas linhas, abordar-se-ão esses dois grandes grupos de competências, com enfoque na atividade judiciária.

Tradicionalmente, a educação formal não se preocupa em dotar o cidadão com competências que não sejam eminentemente técnicas. Seu foco é a aquisição do conhecimento intelectual destinado à utilização no mercado de trabalho, sendo relegada a formação de conhecimentos e habilidades emocionais ao aprendizado psicossocial decorrente das interações humanas em família, na escola e em outros ambientes de convivência social, sobretudo no próprio ambiente de trabalho.

O relevo historicamente conferido à aquisição e ao uso das competências técnicas no recrutamento e na formação de profissionais para o trabalho se evidencia desde a necessidade de demonstrá-las e comprová-las nas etapas de uma seleção ou concurso público, se a vaga a preencher se encontra na administração pública, até a renovação e a reciclagem desses conhecimentos proporcionadas nos treinamentos no ambiente organizacional.

Hard skills representam competências técnicas e intelectuais. Expressam o agrupamento de conhecimentos e habilidades 
desenvolvidas e adquiridas a partir da educação formal, de base científica, perfeitamente quantificáveis e mensuráveis. São competências necessárias para produzir, processar, reter e utilizar informações; relacionam-se à capacidade de raciocinar, de elaborar conceitos, de fazer análises, de planejar, definir estratégias e tomar decisões. (MAXIMIANO, 2000, p. 41-42)

Nos cargos que integram a estrutura judiciária, tais conhecimentos englobam a habilidade de domínio do vernáculo, da apreensão do direito material, do conhecimento das normas disciplinares e regras de organização judiciária, do direito processual e dos precedentes e da jurisprudência, dentre outros saberes formais, competências indispensáveis à execução das tarefas por meio das quais o ordenamento jurídico é, pelo trabalho do Judiciário, aplicado à prestação jurisdicional.

A preocupação com essas competências inicia-se desde o recrutamento, pautado expressamente, no caso do Judiciário e dos demais órgãos públicos, pelas regras constitucionais que normatizam o ingresso em cargos de provimento efetivo e que, durante o exercício de suas funções, demandam um comportamento pautado pela legalidade, impessoalidade, moralidade, publicidade e, sobretudo, pela eficiência, enunciados no art. 37, caput, da Constituição Federal.

O concurso público é exigência constitucional e, na forma como até hoje é estruturada sua realização, busca apurar apenas a quantidade de conhecimento técnico acumulado pelo candidato que aspira a posição. A partir do grau de conhecimento técnico atestado pelo concurso a instituição almeja que as funções inerentes ao cargo sejam desempenhadas com o máximo de eficiência. Contudo, não é esse o resultado que a realidade entrega.

A literatura especializada aponta inúmeros problemas enfrentados pelas organizações com essa forma de seleção e recrutamento, tais como a ausência de motivação, a prática de mudanças periódicas na gestão, a falta de liderança e de autonomia nas decisões, dificuldades de atendimento, excesso de conflitos entre servidores, falta de comprometimento no alcance de metas e a falta de reuniões frequentes, apenas para citar aqueles identificáveis com mais ênfase perante o Judiciário. (SANTOS, 2014, p. 240-241)

Esses problemas se evidenciam em um contexto potencializado pela grande judicialização de disputas que constantemente demanda aumento de produtividade a partir do cumprimento de metas, exigindo 
foco, constância e esforço por parte das pessoas que integram a instituição, em um ambiente interno e externo cada vez mais influenciado pelo dinamismo das mudanças sofridas pelas relações sociais ao longo dos últimos anos.

O cenário desenhado não só dificulta o cumprimento da estratégia judiciária por parte dos agentes públicos, como mostra que apenas o trabalho duro fundado no conhecimento essencialmente técnico não tem conseguido atingir, ao menos sem sacrificios, as metas estabelecidas, o que pode levar a um prejuízo incomensurável da saúde e até mesmo comprometimento da capacidade laborativa desses agentes ${ }^{2}$.

É preciso, pois, criar um ambiente organizacional do qual possa ser extraída a mútua satisfação entre agentes públicos e instituição. Ainda que a falta de qualificação e de atualização de conhecimentos técnicos possa ser provida por meio de investimentos na formação técnica desses profissionais, isso não alcança todos os problemas apontados pela doutrina, cujos exemplos mais corriqueiros são a ausência de motivação e o excesso de conflitos entre servidores, o que evidencia, por si só, a insuficiência do exercício exclusivo de competências duras para o alinhamento da gestão de pessoas à estratégia judiciária na consecução pela eficiência. Faz-se necessário, portanto, desenvolver e integrar no ambiente de trabalho - competências socioemocionais.

Depois de apontar os principais problemas na gestão de pessoas, Santos (2014, p. 241-242) destaca também, em resposta ao rol por ele anteriormente construído, as principais soluções encontradas. Aponta, para o aprimoramento da gestão de pessoas, dentre outras ações e medidas, reconhecer e recompensar servidores, promover auxílio psicopedagógico, aperfeiçoar a comunicação, manter bom clima organizacional, mudar a cultura organizacional, envolver o chefe na escuta e no conhecimento dos subordinados e promover um ambiente saudável de trabalho.

Comum a todas as medidas discriminadas é o fato de que sua implementação não encontra amparo nas competências duras, demandando, ao contrário, o desenvolvimento de outro conjunto de

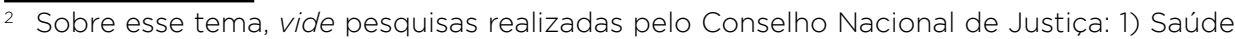
de magistrados e servidores: Resolução CNJ n. 207/2015/ Conselho Nacional de Justiça Brasília: CNJ, 2017; e 2) Saúde de magistrados e servidores: Resolução CNJ n. 207/2015/ Conselho Nacional de Justiça - Brasília: CNJ, 2019.
} 
saberes cuja identificação e promoção se fazem necessárias na gestão de pessoas no Judiciário, visando à melhoria de desempenho em sua atividade-fim.

Essas competências denominam-se brandas ou suaves (soft skills) e não integram a base curricular da academia, mesmo compondo a grade de disciplinas do ensino médio, conforme previsto na Lei n. 9.394, de 20 de dezembro de 1996 (art. 35, § 7ํ), alterada pela Lei n. 13.415, de 16 de fevereiro de 2017. (BRASIL, 1996)

A partir da definição construída pela Organização Mundial de Saúde - OMS, tratam-se tais competências daquelas voltadas à aquisição de habilidades comportamentais, o que proporciona ao agente o enfrentamento de desafios pessoais e laborais munido de uma atitude positiva, reflexiva e maleável, gerando em sua prática comportamentos integrados e capazes de melhorar relações e performances sob perspectivas pessoais e profissionais (ORGANIZAÇÃO MUNDIAL DE SAÚDE, 2013). As competências brandas estão focadas nas pessoas, e não em processos de trabalho.

Enquanto as hard skills se relacionam à execução de um tipo específico de tarefa, as soft skills permeiam todos os momentos da atuação profissional e dos processos de trabalho, sendo essa a razão pela qual sua presença no mundo corporativo contemporâneo tem se mostrado cada vez mais necessária na busca da eficiência e na construção de equipes de alta performance.

No mundo corporativo, a competência dura é um filtro de entrada na carreira enquanto a competência branda é destaque na saída (SABBAG, 2018, p. 39). Vale dizer que as pessoas normalmente são contratadas pelo conhecimento intelectual e técnico sobre as atribuições que irão desempenhar na organização, mas são frequentemente demitidas pela falta de competências intra e interpessoais, tais como autocontrole e comunicação assertiva. Quanto mais se sobe na carreira, mais importante se tornam as competências brandas para gerar o desempenho requerido, na medida em que cargos de liderança demandam a coordenação de equipes. Walker exemplifica tal questão em um caso bem resumido, que vale a pena a transcrição:

Você promoveu, sabiamente, um funcionário de alto desempenho a um cargo de gestão. Seis meses depois, esse astro em ascensão teve uma queda abrupta: ele está sobrecarregado, inseguro e não é respeitado por sua equipe. Por quê? Você provavelmente o 
promoveu com base em sua competência técnica, depois esperou que ele assimilasse as aptidões de gestão por osmose. Mas ele não captou os verdadeiros desafios da gestão - por exemplo, dar poder a outros em vez de se esforçar por uma conquista pessoal. Inseguro para pedir ajuda, ele se volta para dentro. O moral da equipe despenca; a produtividade é ameaçada. Como salvar seu funcionário promissor? (WALKER, 2018, p. 63)

O problema é que comumente para a ascensão na carreira o mérito é perquirido pelo desempenho nas competências duras, ou seja, competências técnicas e intelectuais, relegando-se as competências brandas para um segundo plano. É até compreensível que assim ocorra, pois as hard skills são padronizáveis, fáceis de identificar, mensurar e capacitar, com resultados imediatos. As soft skills, por outro lado, por serem competências relacionais, que envolvem lidar consigo mesmo e com os outros, são difíceis de padronizar, de identificar e mensurar, decorrendo daí a maior necessidade de investimento de tempo no seu desenvolvimento e na obtenção de resultados após o encerramento desse processo. (SABBAG, 2018, p. 37)

No Judiciário, não poderia ser diferente, ante a necessidade de otimização da atuação interna de suas unidades e a potencialidade de o estímulo a tais competências proporcionar a valorização do potencial humano nelas presente e sua mobilização na persecução dos fins estratégicos. Afinal, as competências suaves relacionam-se diretamente com a forma pela qual os individuos se relacionam consigo e com aqueles com quem interagem no âmbito laboral ou fora dele, interferindo na forma como o agente vê e vive a vida, da mesma forma que impacta nas relações de trabalho e na sua produtividade.

Destacando as habilidades socioemocionais mais importantes, Wheeler (2016, p. 28) cita as capacidades de autoconhecimento, de autogestão, automotivação, empatia e habilidades sociais como a comunicação efetiva, a assertividade, a escuta ativa, habilidades de trabalho em equipe, de receber e fazer críticas construtivas, de ser emocionalmente honesto, de expressar emoções apropriadamente e ainda de resolver problemas complexos.

Tais habilidades são expressão do que se denomina inteligência emocional, e sua apreensão e prática pela gestão de pessoas mostra-se capaz de transformar qualitativamente as relações de trabalho, mudar 
o clima organizacional e, conjugada com as habilidades técnicas ou científicas, permitir o cumprimento de modo mais eficiente da missão institucional.

Anote-se ainda que o uso de tais competências produz efeitos positivos não apenas na vida e na produtividade da instituição. Além de viabilizar a mudança da cultura organizacional judiciária, ainda qualificada pela burocracia e pela hierarquia, o desenvolvimento das soft skills trará benefícios também à vida dos próprios agentes públicos na medida em que estarão mais qualificados a melhor entender e responder a si, ao próximo e ao mundo que os cerca, consolidando, assim, ganhos de ordem pessoal aos agentes que as adquirirem.

Referidas competências são ligadas diretamente à maturidade e à personalidade do ser humano, sendo essa a razão pela qual não são adquiríveis por intermédio da educação formal. Podem, entretanto, ser desenvolvidas e apreendidas internamente pela equipe, devendo ficar a missão a cargo de uma liderança verdadeira, menos fundada na autoridade ou no afeto, holística e mais apoiada em uma postura ética e principiológica, exercida com o fim de fomentar o trabalho em grupo, de construir vínculos entre pessoas e integrá-las nos processos de trabalho como parceiros, e não meramente como uma peça da engrenagem. Deverão, portanto, ser os agentes conhecidos, ouvidos, engajados na missão e estimulados a perseguir todos os objetivos, inclusive os pessoais, afetos ao ambiente profissional. (FIGUEIREDO, 2014, p. 151-156)

Dotar o corpo funcional de todos os instrumentais necessários à entrega do produto final da jurisdição em tempo razoável é, portanto, medida que atende aos interesses estratégicos da instituição. O sucesso desse processo de conquista das habilidades socioemocionais, e de seu uso conjugado com as habilidades técnicas, deve ser perseguido pela gestão de pessoas de modo a permitir a formação ou requalificação de equipes capazes de, mesmo em um cenário de grandes cobranças e influências externas negativas, superar problemas e obter bons resultados.

Sendo o Judiciário composto de pessoas, é natural que o funcionamento coordenado, produtivo e eficiente de suas unidades dependa da presença e do desenvolvimento dos dois tipos de competência citadas, pois somente a partir de sua integração ou conjugação, seria possível criar um ambiente de diálogo qualificado 
pelo engajamento cooperativo favorável à superação de dificuldades, resolução de problemas complexos e ao fomento de soluções inovadoras.

A conjugação de tais competências em torno do ideal estratégico constitui ação fundamental no enfrentamento da crise judiciária, trazendo consigo, ainda, benefícios pessoais aos colaboradores da instituição, melhorando os índices de saúde laboral, o clima organizacional e a própria satisfação com o trabalho realizado.

A necessidade da implementação de tal medida perante o Judiciário, em face da busca do seu lucro social, impõe-se na esteira da tendência sofrida pelas organizações privadas, hoje mais conscientes da necessidade de valorização do capital humano e da percepção de que o sucesso dos negócios está diretamente ligado ao desempenho dos colaboradores envolvidos no cumprimento da missão da instituição. (ALBUQUERQUE; LEITE, 2009, p. 69)

Por essa razão, cogita-se que a mudança de mentalidade tocante ao estímulo das competências suaves deva ocorrer tanto nas equipes existentes como implementada logo no início da carreira de seus componentes, facilitando a promoção e a internalização, na cultura da organização, de uma cultura de diálogo, de cooperação e de eficiência ao longo da carreira de servidores e de juízes.

Caso integrassem à grade curricular de treinamentos e da formação inicial disciplinas que estimulassem saberes socioemocionais, passando a ser, inclusive, sua prática objeto da avaliação destinada à instrução dos processos administrativos de vitaliciamento e de estabilidade, mais fácil atualmente se mostraria o enfrentamento das metas que premem, na persecução da eficiência, o Judiciário pela redução do congestionamento de seus acervos.

Cabe, portanto, à governança judiciária conscientizar-se dos benefícios do estímulo e desenvolvimento das boas competências interpessoais, identificar o gap existente em seu quadro funcional e criar estratégia para seu suprimento, em conjunto com a construção das competências técnicas em falta ou deficientes igualmente necessárias à execução estratégia institucional. 


\section{CONCLUSÃO}

Ao longo deste trabalho, buscou-se relacionar o conceito de liderança, atualmente orientado à interação das pessoas, com enfoque no desenvolvimento humano e reflexo na efetividade das atividades organizacionais, com a Política Nacional de Gestão de Pessoas do Poder Judiciário, implementada pela Resolução n. 240, de 9 de setembro de 2016, do Conselho Nacional de Justiça.

Defendeu-se que a liderança deve ser vista como ativo estratégico da organização, em uma perspectiva transversal, perpassando o capital social organizacional (relações sociais, confiança mútua, aprendizado compartilhado), o capital humano (conhecimentos, habilidades, experiências individuais, criatividade) e o capital organizacional (formado pela cultura organizacional, pela reputação, pelos processos de produção e direitos de propriedade intelectual).

Ressaltou-se a importância do papel da gestão de pessoas no cumprimento da estratégia da organização judiciária, defendendo-se a necessidade da estruturação e aplicação de uma política gerencial voltada mais diretamente às pessoas (magistrados, servidores e colaboradores), objetivando a formação de equipes de alto desempenho, a fim de que sejam colhidos resultados positivos na prestação do serviço judicial e, com isso, ver superada a crise de legitimidade por que passa o Judiciário.

A consecução da eficiência do Judiciário deve necessariamente passar por reformulação em sua governança para que essa seja capaz de suscitar o engajamento de seus colaboradores no cumprimento da missão, permitindo assim vencer os desafios trazidos pela modernidade, com efetivo abandono da tradicional rigidez, do hermetismo e da histórica ausência de formação gerencial, elementos tão próprios à cultura organizacional judiciária.

A experiência tem evidenciado que o exercício de competências puramente técnicas não é capaz de entregar o desempenho perseguido pela estratégia judiciária, dada a incapacidade da exclusiva movimentação desses recursos intelectuais em integrar plena e eficazmente os processos de trabalho para a prática dos quais são necessários, e a incapacidade também de promover o engajamento dos agentes e das equipes na consecução dos propósitos definidos. 
Da mesma forma, o desenvolvimento de inteligência emocional por si só, desacompanhado dos conhecimentos científicos indispensáveis à execução dos atos técnicos por meio dos quais se presta a jurisdição, também não se presta à superação da crise judiciária. Para que isso ocorra, é importante que ambos os grupos de habilidades sejam conjugados para produzir o desempenho funcional e a produtividade visadas pela instituição no cumprimento de seus objetivos.

A reformulação qualitativa da política de gestão de pessoas à luz das técnicas praticadas na iniciativa privada, mediante introdução, desenvolvimento conjugado e estímulo das hard e soft skills, representaria importante passo para a consecução, de forma clara e inequívoca, do cumprimento e alcance pleno das estratégias, metas e objetivos de gestão.

Dadas tais premissas, e considerada a ausência de formação apropriada na academia, urge propor a reformulação dos processos de seleção e formação de magistrados e servidores para neles desenvolver as soft skills, medida capaz de viabilizar, uma vez apreendidas pela cultura organizacional, a construção de equipes de alta performance no Judiciário e a otimização de seu recurso mais valioso na busca do desempenho ótimo.

Sendo intrínsecas à concepção de organização, as noções de relacionamento intersubjetivo, de cooperação e de estratégia, bem como a certeza de que toda organização existe para cumprir objetivos certos, concretizar esse relevante ajuste na gestão de pessoas da instituição judiciária melhor instrumentalizaria no desencargo de sua missão institucional, permitindo-Ihe alcançar a busca da eficiência do efetivo acesso à ordem jurídica justa, e na materialização dos direitos de cidadania pela população brasileira. 


\section{REFERÊNCIAS}

ALBUQUERQUE, L. G. de; LEITE, N. P. (org.). Gestão de pessoas: perspectivas estratégicas. São Paulo: Atlas, 2009.

ALEXANDRE, M. L. et al. Considerações sobre planejamento estratégico na gestão pública: parâmetros e mudanças. In: III SIMPÓSIO DE EXCELÊNCIA EM GESTÃO E TECNOLOGIA. 2006. Anais do... Disponivel em: https://www.aedb.br/seget/arquivos/ artigos06/918_Consideracoes\%20sobre\%20०\%20planejamento\%20 estrategico.pdf. Acesso em: 1 maio 2021.

ARAÚJO, L. C. G. de; GARCIA, A. A. Gestão de pessoas: edição compactada. São Paulo: Atlas, 2010.

BRASIL. Constituição (1988). Constituição da República Federativa do Brasil. Brasília, DF: Presidência da República, 1988. Disponível em: http://www.planalto.gov.br/ccivil_03/constituicao/constituicao.htm. Acesso em: 11 jan. 2021.

BRASIL. Emenda Constitucional n. 45, de 30 de setembro de 2004. Brasília, DF: Presidência da República, 2004. Disponível em: http:// www.planalto.gov.br/ccivil_03/constituicao/emendas/emc/emc45.htm. Acesso em: 2 fev. 2021.

BRASIL. Lei n. 9.394. Lei de Diretrizes e Bases da Educação. Brasília, DF: Presidência da República, 1996. Disponível em: http://www. planalto.gov.br/ccivil_03/leis/19394.htm. Acesso em: 11 fev. 2021.

CHANG Jr., João; SANTOS, Suzana B. de S. A análise do ambiente interno: competências e capacidades. In: ALBUQUERQUE, Lindolfo G. de. LEITE, Nildes P. (org.). Gestão de pessoas: perspectivas estratégicas. São Paulo: Atlas, 2009. p. 27-48.

CONSELHO NACIONAL DE JUSTIÇA (Brasil). Metas nacionais. Brasília, DF: Conselho Nacional de Justiça, 2021. Disponível em: https://www. cnj.jus.br/gestao-e-planejamento/metas/. Acesso em: 23 maio 2021.

CONSELHO NACIONAL DE JUSTIÇA (Brasil). Portaria n. 59, de 23 de abril de 2019. Brasília, DF: Conselho Nacional de Justiça, 2019. Disponível em: https://atos.cnj.jus.br/files//portaria/ portaria_59_23042019_24042019104402.pdf. Acesso em: 24 maio 2021. 
CONSELHO NACIONAL DE JUSTIÇA (Brasil). Resolução n. 198, de 1ํ de julho de 2014. Brasília, DF: Conselho Nacional de Justiça, 2014. Disponível em: https://atos.cnj.jus.br/files/resolucao_comp_198_01072 014_25032019141511.pdf. Acesso em: 24 maio 2021.

CONSELHO NACIONAL DE JUSTIÇA (Brasil). Resolução n. 240, de 9 de setembro de 2016. Brasília, DF: Conselho Nacional de Justiça, 2016. Disponível em: https://atos.cnj.jus.br/atos/detalhar/atosnormativos?documento=2342. Acesso em: 10 fev. 2021.

CONSELHO NACIONAL DE JUSTIÇA (Brasil). Resolução

n. 325, de 29 de junho de 2020. Brasília, DF: Conselho Nacional de Justiça, 2020. Disponível em: https://atos.cnj.jus.br/files/ original182343202006305efb832f79875.pdf. Acesso em: 24 maio 2021.

CONSELHO NACIONAL DE JUSTICCA (Brasil). Resolução n. 70, de 18 de março de 2009. Brasília, DF: Conselho Nacional de Justiça, 2009. Disponível em: https://atos.cnj.jus.br/atos/detalhar/118. Acesso em: 10 fev. 2021.

ENFAM. Apêndice A: Apresentação sistematizada das diretrizes pedagógicas. Brasília: Enfam, 2017. Disponível em: https://www.enfam. jus.br/wp-content/uploads/2017/12/Res_7_2017_Enfam_Diretrizes_ Pedagogicas_Enfam_-Apendice_A.pdf. Acesso em: 10 fev. 2021.

FIGUEIREDO, L. V. S. de. Gestão em Poder Judiciário: administração pública e gestão de pessoas. Curitiba: CRV Editora, 2014.

FLEURY, M. T. L.; FLEURY, A. Construindo o conceito de competência. Rev. adm. contemp., Curitiba, v. 5, n. spe, p. 183-196, 2001. DOl: http://dx.doi.org/10.1590/S1415-65552001000500010. Disponivel em: http://www.scielo.br/scielo.php?script=sci_ arttext\&pid=S1415-65552001000500010\&lng=en\&nrm=iso. Acesso em: 23 maio 2021.

HUNTER, James C. O monge e o executivo. Rio de Janeiro: Sextante, 2004.

KANAANE, R.; FIEL FILHO, A.; FERREIRA, M. das G. (org.). Gestão pública. São Paulo: Atlas, 2010.

LIMBERGER, T.; KOSSMANN, E. L. O princípio constitucional da eficiência ante o Estado (in)suficiente. Revista de Direito 
Administrativo, Rio de Janeiro, v. 273, p. 287-311, 2016. Disponível em: https://bibliotecadigital.fgv.br/ojs/index.php/rda/article/view/66664. Acesso em: 24 maio 2021.

LODI, J. B. As funções do executivo. Rev. adm. empres., São Paulo, v. 11, n. 3, p. 119-121, July/Sept. 1971. DOl: https://doi.org/10.1590/ S0034-75901971000300014. Disponível em: https://www.scielo. $\mathrm{br} / \mathrm{scielo}$. php? script=sci_arttext\&pid=S0034-75901971000300014. Acesso em: 10 fev. 2021.

MATIAS-PEREIRA, J. Manual de gestão pública contemporânea. 4. ed. São Paulo: Atlas, 2012.

MAXIMIANO, A. C. A. Introdução à administração. 5. ed. São Paulo: Atlas, 2000.

ORGANIZACCÃO MUNDIAL DE SAÚDE. Skills for health: skills-based health education including life skills: an important component of a Child-Friendly/Health-Promoting School. Geneva: WHO, 2003.

Disponível em: https://www.who.int/school_youth_health/media/en/ sch_skills4health_03.pdf. Acesso em: 5 fev. 2021.

SABBAG, Y. P. Competências em gestão. Rio de Janeiro: Alta Books Editora, 2018.

SANTOS, C. S. dos. Introdução à gestão pública. São Paulo: Saraiva, 2010 .

SANTOS, C. S. dos. Introdução à gestão pública. São Paulo: Saraiva, 2014.

WALKER, C. A. Salvando os gestores inexperientes deles mesmos. In: GOLEMAN, D. et al. Gerenciando pessoas. Tradução de Paulo Geiger. Rio de Janeiro: Sextante, 2018. p. 61-76. (Harvard Business Review).

WHEELER, R. E. Soft Skills: the importance of cultivating emotional intelligence. Chicago, AALL Spectrum, [s./.], p. 28-31, Jan./Feb. 2016. 